\title{
LA LEGÍTIMA DEFENSA ANTE LA INCONSTITUCIONALIDAD DEL EMBARGO FISCAL PRECAUTORIO Y SU REMATE
}

\author{
THE LEGITIMATE DEFENSE IN THE FACE OF UNCONSTITUTIONALITY OF THE \\ PRECAUTIONARY TAX LIEN AND ITS AUCTION
}

Horacio Puentes Medina

Universidad Tecnológica del Norte de Aguascalientes Aguascalientes, México

ORCID: 0000-0002-8080-4337

Correo electrónico: Horacio.puentes@utna.edu.mx

Marcela Rocha López

Universidad Tecnológica del Norte de Aguascalientes

Aguascalientes, México

ORCID: http://orcid.org/0000-0002-1880-7633

Correo electrónico: marcela.rocha@utna.edu.mx

\section{RESUMEN}

Uno de los temas más importantes dentro del Derecho Tributario Mexicano es el remate de bienes que se establece en el artículo 155 fracción I del Código fiscal Federal, dentro del embargo precautorio. Bajo esa premisa, existe una laguna inmensa cuando se bloquean las cuentas bancarias de los contribuyentes y no son susceptibles de almonedas, por lo que no se puede justificar el no llevar a cabo la autoridad el debido proceso que marcan los artículos $1 .^{\circ}, 14 .^{\circ}$ y $16 .^{\circ}$ de la Constitución mexicana. Esta investigación consiste en hacer una comparación entre las leyes tributarias de México y Perú relacionadas con la legítima defensa ante la inconstituicionalidad del embargo fiscal precautorio y su remate. Por un lado, se evalúa cómo se aplican las leyes tributarias y su debido proceso en materia del embargo precautorio en el terriotorio mexicano hacia los contribuyentes por el incumplimiento de sus obligaciones fiscales. Por otro lado, se señala que el Código Tributario de la República del Perú indica las formas de embargar o trabar al ejecutor coactivo, y que toda persona tiene derecho al secreto, a la inviolabilidad de sus documentos privados y a una legítima defensa. Se concluye que en la República del Perú se respeta el derecho a la garantía de audiencia, al debido proceso, al principio del derecho a la posesión y al de propiedad, lo que en el Código fiscal de la Federación del Estado mexicano no contempla.

Palabras clave: Remate de bienes; embargo precautorio; cuentas bancarias; legítima defensa.

\begin{abstract}
One of the most important issues within Mexican Tax Law is the auction of assets that is established in article 155 section I of the Federal Tax Code, within the precautionary attachment. Under that premise, there is an immense gap when bank accounts of taxpayers are blocked and are not susceptible to auction, so it cannot be justified that the Mexican authority does not carry out due process which is established by articles $1,14 .^{\circ}$ and $16 .^{\circ}$ of the Mexican Constitution. This investigation consists in making a comparison between the tax laws of Mexico and Peru related to the legitimate defense against the unconstitutionality of the precautionary tax embargo and its auction. On the one hand, it is evaluated how the tax laws are applied and their due process in the matter of the precautionary attachment in Mexican territory to taxpayers for breach of their tax liabilities. On the other hand, it is pointed out that the Tax Code of the Republic of Peru indicates the ways of seizing or locking the coercive executor, and that everyone has the right to secrecy, the inviolability of their private documents and a legitimate defense. It is concluded that in the Republic of Peru the right to the guarantee of hearing, due process, at the beginning of the right to possession and property is respected, which is not contemplated in the Fiscal Code of the Federation of the Mexican State.
\end{abstract}

Keywords: Property auction; precautionary attachment; bank accounts; legitimate defense.

(c) Los autores. Este artículo es publicado por la Revista Quipukamayoc, Universidad Nacional Mayor de San Marcos. Este es un artículo de acceso abierto, distribuido bajo los términos de la Licencia Creative Commons Atribución-NoComercial-Compartirlgual 4.0 Internacional.(http://creativecommons.org/licenses/by-nc-sa/4.0/), que permite el uso no comercial, distribución y reproducción en cualquier medio, siempre que la obra original sea debidamente citadas. 


\section{INTRODUCCIÓN}

El remate de bienes que se establece dentro del proceso del embargo precautorio en términos del artículo 155 fracción I del Código fiscal Federal (CFF), no puede ser aplicado al dinero ni a los depósitos de las cuentas bancarias, ya que los activos financieros no son susceptibles de subasta pública por parte de la autoridad recaudadora, por lo que se deja a los contribuyentes sin legítima defensa. Esto resultaría inconstitucional y violatorio de sus derechos humanos fundamentales y de las garantías individuales señalados en los articulados $1 .^{\circ}, 14 .^{\circ}$ y $16^{\circ}$ de la Constitución Política de los Estados Unidos Mexicanos (CPEUM), al rebasar la jerarquía de las leyes y al acceso a la justicia.

La autoridad fiscal no ha emitido ninguna regla en particular cuando se bloquean los depósitos de la cuentas bancarias, por lo que el causante no puede disponer de sus bienes económicos y financieros para sufragar sus obligaciones. Esta situación no está contemplada dentro del apartado 155 fracción I del CFF, por lo que resulta absurdo que esta laguna en la ley no haya sido reparada por los congresistas ni por las autoridades recaudadoras, puesto que está muy a favor del Estado y, en consecuencia, ya no es objetiva e imparcial al momento de ser aplicada, lo que deja en un desamparo total al contribuyente al no existir un medio dentro del CFF de oponer defensa en ese sentido.

Es muy claro que dicho proemio jamás fue diseñado desde su inicio para el embargo de los bienes económicos y financieros, sino para los bienes muebles e inmuebles, buscando en todo momento asegurar la negociación del gobernado, pero con el trascurso del tiempo se fue modificando el CFF en el tema de la incautación de los depósitos bancarios, sin regular hasta el momento los legisladores a estos activos monetarios de una manera especial dentro del Procedimiento Administrativo de Ejecución (PAE), ya que estos bienes bancarios son de fácil realización y, por lo tanto, no son susceptibles de almonedas de acuerdo a la propia naturaleza del circulante.

Es muy peligroso que dentro del PAE se le desnaturaliza al contribuyente, primero, de la posesión; luego, del uso; $y$, por último, del beneficio de utilizar esos activos financieros sin permitirle el acceso a una legítima defensa, ya que el propio CFF en su apartado 127 señala que únicamente se puede interponer una recurso hasta el remate de los bienes inmuebles, pero nunca señala el caso particular de los bienes monetarios en su momento procesal oportuno para llevar a cabo el medio de defensa adecuado a los hechos.

El problema de esta indagación es cómo decretar la legítima defensa por parte de los Tribunales Federales ante la inconstitucionalidad del embargo precautorio en materia tributaria que se efectúa a través del PAE y que está señalado en el CFF, en sus artículos del 155 y 156-Bis. Este interés surge debido al perjuicio que dicho embargo ocasiona a los contribuyentes, por no poder combatirlo sino hasta la publicación del remate de los bienes en términos del artículo 127 del citado ordenamiento y, por ello, quedan en un total estado de indefensión e incertidumbre los causantes, sin que se pueda estimar el plazo o término que pueda tardar el trámite administrativo de la publicación de la subasta pública, que de manera interna efectúa la autoridad ejecutora sobre los bienes incautados.

La incautación de los bienes señalados en los artículos 155 y 156 del CFF, donde se fundamenta el procedimiento administrativo de ejecución y que lleva a cabo la autoridad administrativa en contra de los gobernados en materia fiscal, quebranta los derechos y las garantías individuales que marcan los artículos $1 .^{\circ}, 14 .^{\circ}$ y $16 .^{\circ}$ constitucionales de los causantes, en virtud de que se le otorga a la autoridad el derecho de señalar bienes de fácil realización o venta sin el consentimiento del causante, y extraerlos de manera indebida.

Los activos que traba la autoridad fiscalizadora son: el dinero, los metales preciosos, los depósitos bancarios o cualquier otro depósito en moneda nacional o extranjera de alguna cuenta crediticia que tenga el contribuyente a su nombre, sin tomar en cuenta el origen de los recursos que le fueron depositados a las cuentas bancarias del gobernante, es decir, se le desnaturaliza al contribuyente del uso y del beneficio de utilizar esos activos financieros que son necesarios para la operación periódica de la compañía, sin previamente haber sido vencido en juicio federal el contribuyente mediante resolución judicial a favor del Servicio de Administración Tributaria (SAT), dejando al causante en un total estado de indefensión al sujeto pasivo y a su negociación, y causando un daño de difícil reparación en términos del artículo 133 de la Ley de Amparo vigente, ya que el gobernado no puede efectuar el pago de los deberes contraídos con sus trabajadores, proveedores, acreedores diversos y, sobre todo, no puede cumplir con el pago de sus impuestos y contribuciones en términos del proemio 31 fracción IV de la Constitución Federal.

La forma tan excesiva y arbitraria en que la autoridad fiscalizadora actúa dentro del PAE al ejercer sus facultades discrecionales que la norma le otorga dentro de los articulados 36, 133A y 141 fracción V del CFF al decomiso de los depósitos de las cuentas bancarias. Estas acciones son aplicadas excesivamente como medio de presión al contribuyente, con el objeto de que el individuo se aterrorice y que caiga en un estado de desorden emocional y perturbación permanente, ocasionándole un estrés postraumático que no le permita al causante tomar decisiones firmes y contundentes, sino lo contrario, caer en equivocaciones 
por malas decisiones, sin embargo, a la autoridad fiscalizadora no le interesa la situación jurídica, económica y emocional del causante. Su objetivo es que la Secretaría de Hacienda y Crédito Público (SHCP) logre el importe de la meta que se propuso al inicio del año sobre el importe de la recaudación señalada en la Ley de Ingresos de la Federación (LIF) de acuerdo con lo que fue planteado al Congreso de la Unión y al Ejecutivo Federal.

El Estado siempre ha oprimido a sus gobernados, ya que desde la edad antigua se conoció al depósito bancario como anticipo de un pago y se descubría como un hecho comprobado en lugares como Mesopotamia, durante el año 3400 a.C., y en Babilonia, en el año 2250 a.C. Durante el siglo VII a.C., se utilizaron documentos para abordar a las actividades bancarias y se crea por primera vez el certificado de banco, las letras de cambio, las órdenes de pago - los ahora títulos de crédito- y nace la administración de bienes en el año 650 a.C. creada por los Babilonios.

En el año de 620 a.C., en Lidia - un país del Asia menor- dentro de la provincia de Éfeso surge la invención de la moneda y se acuña por primera vez en el mundo. El dinero se elaboraba en metal de electro u oro blanco, y fue aprovechado en medida por Grecia y otros reinados a través de un Trapezitie. Este era un griego especialista en el manejo del dinero, el cual era entregado a los Daneístas quienes eran los encargados de la colocación de depósitos. Durante el siglo VI a.C., se crearon por primera vez casas comerciales (bancos) para el manejo del dinero, destacando las ciudades de Sippar y Nippur, situadas al sur de Babilonia. Ambas metrópolis prohibían el cobro de intereses a sus habitantes y el decomiso de sus bienes monetarios, con excepción a los extranjeros, ya que así lo establecía la Ley de Moisés. Sin embargo, durante el siglo V a.C., se utilizaron efemérides (libros de diario y mayor) para el registro de los procesos contables financieros y económicos, sustituyéndose a las tablas de arcilla que se utilizan para el registro de las cuentas bancarias y sus movimientos bancarios. Filostéfono, el primer gran banquero griego, era un hombre de temperamento intelectual, enérgico y caprichosamente irrigable que gobernó Inglaterra (Guerra, 2002). En el siglo VI a.C formó parte de las primeras normas aplicables a los actos comerciales y bancarias del mundo y las incorporó al Derecho Romano (Rojas, 2013).

Durante el reinado de Carlos II de Inglaterra, Escocia e Irlanda (Reino Unido), este se encontraba fuertemente endeudado, a tal punto, que en 1672 a.C. se vio obligado a suspender los pagos de la corona real y, en consecuencia, debía devolver las sumas que fueron impagadas a los banqueros que le otorgaron créditos (Chesterton, 2016). Esto ocasionó que desarrollen y mejoren los movimientos comerciales en Roma y es así como nace la función bancaria a través de los trapezita griegos, motivo por el cual los romanos argentarius (banqueros) y los nummularius (cambistas) decidieran aplicarse en las actividades bancarias tales como: cambios de monedas, usos del transporte del dinero, depósitos regulares e irregulares, servicios de caja en la compra y venta de muebles e inmuebles, y en subastas públicas, incluyendo el embargo de dinero u operaciones comerciales y bancarias, pero su principal actividad era el préstamo como inversión de capital propio y ajeno (Rojas, 2013).

En México poco se sabe del embargo precautorio de los bienes, ya que sólo le antecede la época de la conquista de 1519 a 1521, donde afectaron profundamente a Mesoamérica los españoles durante el reinado de la Nueva España. En esa época un joven de nombre Hernán Cortes de Monroy y Pizarro Altamirano, incautó y despojó de todos sus bienes al imperio indígena Azteca, luego al imperio Inca hasta llegar a parte de Sudamérica.

Entre los años 1519 y 1522, Cortés pasó de ser un subalterno en rebeldía a quedar absuelto de todo cargo y obtener del rey de España el nombramiento de gobernador y capitán general de las tierras que había conquistado, como premio a todo lo que se había incautado, secuestrado o embargado del suelo mexicano. La totalidad del botín de guerra fue enviado al rey para devolverle el favor por financiar la navegación o travesía que se realizó directamente desde España hasta el territorio del Salvador, y del regreso desde el golfo de México por el canal de las Bahamas hacia Europa (Céspedes, 2009).

Después del triunfo de la Independencia de México, y con la entrada del Ejército Trigarante al Zócalo de la capital Mexicana el 27 de septiembre en 1821, el territorio cambió totalmente de ser un pueblo conquistado, saqueado, incautado y embargado por más de 320 años por España, a una república democrática e independiente; sin embargo, no fue hasta después de 1921 con el término de la Revolución mexicana que se inicia el proceso de la separación real de poderes, esto con el objeto de repartir la tierra durante 1922 y 1929, haciendo justicia por la que tanto se había luchado (Tovar y Mas, 2019).

Con la entrada en vigor del CFF y sus modificaciones en los años 1938, 1966, 1983 y 2000, se cambió de forma radical la política fiscal monetaria que durante más 62 años prevaleció en el Gobierno mexicano, durante la cual difícilmente se aplicaba embargos de cuentas bancarias a políticos, exgobernadores, jefes de Estado, así como a gente muy cercana a la Presidencia de la República; sin embargo, con los convenios de colaboración en materia tributaria que se han firmado con otros países y derivado de la reforma a las llamadas operaciones inexistentes que son soportadas mediante trasferencia de fondos, la autoridad fiscalizadora logró incautar en el 2017 la cuantía de 
118,400 millones de pesos provenientes del embargo de cuentas bancarias (Martínez, 2011).

Para una comprensión más precisa de la palabra bloqueo, el Diccionario de la lengua española la describe como acción y efecto de bloquear, bloquear a su vez es definido como: el dicho de una autoridad competente para inmovilizar una cantidad o un crédito, privando a su dueño de disponer de ellos total o parcialmente por cierto tiempo. Visto todo lo anterior, aunque ninguno de los dos términos se ajusta exactamente al fenómeno que trataremos de analizar, el que más se le acerca es el de embargo, dado que se define como a retención, traba o secuestro de bienes por mandato de juez o autoridad competente (Real Academia Española, 2014).

Se presentan muchas deficiencias por parte del SAT al momento de llevar a cabo el PAE, sin embargo, esta investigación hace referencia en particular a la incautación de la cuenta bancaria de los contribuyentes y a la violación incesante de los derechos y garantías de los gobernados señalados en los proemios $1 .^{\circ}, 14 .^{\circ}$ y $16^{\circ}$ constitucionales que se encuentran intrínsecamente vinculados al remate de bienes, acto que se encuentra establecido dentro del debido proceso en el embargo precautorio señalado en el artículo 155 fracción I CFF, y que es aplicable al caso en particular a la traba que efectúa la autoridad recaudadora a los depósitos monetarios efectuados a las cuentas bancarias de los contribuyentes sin previa notificación legal dentro de los tres días hábiles siguientes al que realizó su acto.

Además, de que estas acciones no son aptas para llevar una diligencia por un remate de bienes y, por lo tanto, tampoco se adecúa a una subasta pública, y muchos menos a una almoneda, se le deja al contribuyente sin el derecho a un legítima defensa en términos del artículo 17 de nuestra Carta Magna. Por ello, resulta inconstitucional la traba de bienes que no son susceptibles de almoneda pública de acuerdo con lo señalado en los articulados 155 fracción I y 156-Bis del CFF, por no señalar de manera precisa el debido proceso que se llevará a cabo en el caso de los bienes monetarios el propio ordenamiento jurídico, y sobre todo no menciona cuál es medio idóneo que se puede utilizar para alcanzar una legítima defensa en términos de ley, por una violación directa a los derechos humanos y garantías individuales consagradas en los artículos $1 .^{\circ}, 14 .^{\circ}$ y $16 .^{\circ} \mathrm{de}$ la Constitución Federal, y lo que señala el proemio 21, numerales 1 y 2 de la Comisión Americana Sobre Derechos Humanos (CASDH).

Es inaudito que en pleno siglo XXI se trate a un contribuyente como un vil delincuente sobre presunciones que no han sido comprobadas por la autoridad fiscalizadora, utilizando como fundamentos los proemios $59,60,61,62$,
63 y 68 del CFF. Sin embargo, de estas presunciones, el mando se empodera para realizar el embargo precautorio de las cuentas bancarias sin haberle otorgado el derecho de audiencia al contribuyente. Primero obliga a la institución financiera a que bloquee el activo bancario y, hasta que el contribuyente pretenda disponer de sus fondos económicos, se puede percatar que dicho bien monetario ya no está en la cuenta bancaria o, simple y llanamente, se encuentra secuestrado, por el solo hecho de presumir que el contribuyente omite registrar adquisiciones en su contabilidad, actos o actividades, y que estas fueran determinadas por las autoridades fiscales.

Sin embargo, dichas autoridades deberán probar los hechos que motiven los actos o resoluciones cuando el afectado los niegue lisa y llanamente, a menos, que la negativa implique la afirmación de otro hecho, lo que en el caso en estudio no sucede, porque la autoridad ejecutora primero embarga utilizando de fundamento el artículo 155 fracción I del CFF, el cual señala cómo decomisar el dinero, los metales preciosos y los depósitos bancarios, siempre que los mismos sean de fácil realización o venta, pero nunca toma en cuenta que ese mismo ordenamiento dé al contribuyente o a la persona con quien se entienda la diligencia de embargo el derecho a señalar los bienes en que éste se deban trabar, luego entonces, la autoridad fiscalizadora en ningún momento respeta el debido proceso constitucional y legal que le marcan las leyes secundarias.

Martínez (2011) señala que:

Dentro de la Obra la Constitución Política de los Estados Unidos Mexicanos Comentada que los derechos humanos son inherentes y que las garantías que tiene el ser humano, por el solo hecho de ser mexicano para su protección no podrán restringirse ni suspenderse, salvo en los casos y bajo las condiciones que esta Constitución establece, sin embargo, el imperio gubernamental tiene en todo momento la obligación de promover, respetar, proteger y garantizar los derechos humanos de conformidad con los principios de universalidad, interdependencia, indivisibilidad y progresividad de acuerdo con el Tratado Federal (p.3).

Es por eso que los Abogados, Armienta y Armienta (2010) plantean que:

Una vez iniciado un juicio contencioso administrativo en contra de la Autoridad Administrativa, es necesaria adoptar una medida cautelar que será instaurada por parte del Juzgador con el objeto de mantener la situación de un hecho jurídico existente en su estado original, quedando a juicio del Juez 
o Magistrado instructor la valoración de los daños $y$ perjuicios inminentes que puedan ocasionarle al causante el Servicio de Administración Tributaria, ya que al momento de trabarle o embargarle y su caso extraer los bienes financieros y monetarios de las cuentas bancarias del causante por parte del mando fiscalizador lo dejan en un total estado de indefensión e incertidumbre jurídica, lo que provoca al sujeto pasivo de la relación tributaria, una violación directa a sus derechos humanos y garantías individuales consagradas en los artículos $1 .^{\circ}, 14 .^{\circ} y$ $16 .^{\circ}$ Constitucionales, ya que la Doctrina Procesal Civil ha señalado que para que se lleve el embargo precautorio requiere dos condiciones: la sospecha de fuga del deudor y además se debe justificar por el acreedor un fumus boni juris, es decir, la apariencia del buen derecho (pp.86-68).

Es así como Pérez, V. (2011) nos plantea que:

Para que proceda la inconstitucionalidad de una ley, cuando la base elemental que soporta la hipótesis de cualquier defensa en una controversia legal es la argumentación, la cual debe fundamentarse en indagar hechos, averiguar teorías y hacer las comparaciones respectivas sobre el tema del embargo precautorio siempre y cuando no afecten el interés de terceros como es el caso de los trabajadores al momento en que se les deje de pagar la nómina, a los proveedores, acreedores bancarios por el cumplimiento de sus obligaciones, etc. (p.2-8).

En otros vocablos que Weston (2001) ha manifestado, se puede resaltar que se debe convencer al juzgador ofreciendo un conjunto de razones o de pruebas en apoyo de una conclusión con el objeto de tener un mejor resultado o en su caso un mayor beneficio.

En pocas palabras, para argumentar la inconstitucionalidad del procedimiento contencioso administrativo señalado dentro de los proemios 145 al 196-B del CFF sobre acciones que realmente perjudican la operación natural de la negociación, por ejemplo, el embargo de las cuentas bancarias, y que si llegara a suceder, no se tendría recurso alguno sino hasta su remate para hacer efectivo un medio de defensa adecuado que le permita la liberación parcial o total, lo cual es inaudito, ya que el dinero o el saldo que se presenta dentro de la cuenta bancaria solo refleja la disponibilidad de utilizar el activo circulante como más le convenga al contribuyente para cubrir las necesidades más básicas de cualquier negocio o comercio, con el objeto de seguir avanzando de manera continua en el crecimiento de la negociación y el cumplimiento de sus obligaciones adquiridas.
Es muy importante aprender a pensar críticamente sobre los motivos del embargo de las cuentas bancarias señaladas en el artículo 155 fracción I del CFF, buscando los argumentos necesarios que demuestren las acciones y hechos de los contribuyentes en materia tributaria, y que se encuentre debidamente respaldado en códigos sustantivos y adjetivos, en leyes y tratados internacionales para ser utilizados con maestría y en beneficio de la sociedad, aportando a cada medio de defensa los elementos necesarios para soportar las ideologías lógico-jurídicas, y que el actor deberá indicar al momento de presentar su controversia señalando con toda a los contribuyentes en sus los derechos humanos, en sus garantías individuales, al establecer el artículo 155 fracción I mayores cargas y requisitos que los exigidos en la Ley de Amparo (Pérez, 2011).

Al no establecerse un medio de defensa dentro de la norma jurídica en contra del embargo de las bancarias, Carrasco (2000) señala que la única forma de defenderse en contra de los actos realizados por la Autoridad Administrativa a través del embargo precautorio, es por medio del amparo indirecto, ya que el CFF establece mayores cargas y requisitos que los exigidos o los establecidos dentro del Código Civil Federal, ya que el causante no podría esperar tanto tiempo para volver a contar con sus activos para utilizarlos, sino hasta el momento procesal oportuno, el cual se da en cuanto inicia el procedimiento para la convocatoria de las almonedas por medio de la cual se llevará el remate de los bienes del contribuyente que fueron trabados, situación que es inaplicable para la inmovilización de los depósitos bancarios y de su disponibilidad en términos del proemio 155 fracción I del CFF, en virtud de que la Suprema Corte de Justicia de la Nación así determinó mediante la Jurisprudencia 17/98 aprobada por la Segunda Sala en sesión privada del 20 de marzo de 1998 (Suprema Corte de Justicia de la Nación, 2011), ya que de lo contrario sería totalmente improcedente el Juicio de Amparo Indirecto en Materia Fiscal, y en ese sentido no se podría lograr decretar la Inconstitucionalidad solicitada por el quejoso al más alto Tribunal Colegiado en México, por la violación directa a sus derechos y garantías individuales señaladas en los preámbulos $1 .^{\circ}, 14 .^{\circ}$ y $16^{\circ}$ de la CPEUM, a través de la actuación de ejecución apremiante realizada al Contribuyente por parte de la Autoridad Administrativa, mediante el Procedimiento Económico Coactivo (PEC) sin aún haber vencido en juicio (Carrasco, 2000).

Asimismo, Jiménez (2000) manifiesta en su obra que:

El acto administrativo y su ejecutoriedad como un privilegio o facultad pública del estado en virtud del cual él mismo puede disponer y llevar a cabo la ejecución de sus actos, lo que en sí excluye la necesidad de que la autoridad fiscalizadora o hacendaria tenga que acudir ante los órganos jurisdiccionales para 
lograr de éstos la ejecución de los mismos ante los contribuyentes (pp. 317-328).

\section{CONCLUSIONES}

En la actualidad, la Secretaria de Hacienda y Crédito Público (SHCP) a través de la Unidad de Inteligencia Financiera (UIF) del Gobierno federal ha congelado aproximadamente la cuantía de 4 millones 600 mil pesos y 42 millones de dólares en 553 cuentas bancarias en lo que va del año a nivel nacional. El titular de la UIF, Santiago Nieto Castillo, ha señalado que un total de 113 denuncias se encuentran relacionadas con posibles casos de lavado dinero; además, en el ámbito nacional, se ha dado a conocer a las autoridades administrativas algunos temas vinculados con defraudación fiscal o por conductas que tienen que ver con el ámbito administrativo. Entonces, se puede concluir que la traba del dinero es una forma unilateral de aplicar la ley por parte de la autoridad administrativa federal dentro del sistema jurídico mexicano, sin mediar algún documento que así lo señale en términos del artículo 14 Constitucional, omitiéndose por completo el requisito máximo de ley establecido en nuestra CPEUM. Es muy importante destacar al respecto que el Código Tributario de la República del Perú (Baldeón, Roque y Garayar, 2009) en su apartado 118 del Título II referente al procedimiento de cobranza coactiva sobre el tema en particular de las medidas cautelares, se indican las formas de embargar o trabar del ejecutor coactivo, y se señala que es a través de la retención de valores y fondos en las cuentas corrientes, depósitos, custodia y otros. Sin embargo, existen limitaciones dentro de los proemios 10 y 23 del Capítulo I de los derechos fundamentales de la persona instaurados en la Constitución Política de Perú (Villarán, 2016) donde toda persona tiene derecho al secreto, a la inviolabilidad de sus documentos privados y a una legítima defensa, en ese sentido, los libros, comprobantes y documentos contables y administrativos están sujetos a inspección o fiscalización de la autoridad competente, de conformidad con la ley, por lo que las acciones que se realicen respecto a los escritos no pueden permitir su sustracción o incautación, salvo por orden judicial, cumpliendo las formalidades de todo procedimiento. Por ello, se concluye que en la República del Perú, se respeta el derecho a la garantía de audiencia, al debido proceso, a la posesión y a la propiedad, ya que antes de que la autoridad pretenda incautar, retener, bloquear o embargar algún activo financiero, deberá tener una orden jurisdiccional emitida por un juez o magistrado que funde y motive su competencia, y señale con toda oportunidad el contenido del acto de molestia para que el gobernado no quede en un estado total de indefensión e incertidumbre jurídica.

\section{REFERENCIAS BILIOGRÁFICAS}

Armienta, G., \& Armienta, G. (2010). Justicia Fiscal y Administrativa. Una visión procesal. México D.F.: Editorial Porrúa.

Baldeón, N., Roque, C. \& Garayar, E. (2009). Código Tributario Comentado. Lima: Gaceta Jurídica.

Carrasco, H. (2000). Amparo en Materia Fiscal. México D.F.: Oxford University Press Harla.

Céspedes, G. (2009). América Hispánica (1492-1898). Madrid: Marcial Pons Historia.

Chesterton, G. K. (2016). Pequeña Historia de Inglaterra. Sin ciudad de impresión: Librodot. Recuperado de: https://www.shu.edu/chesterton/upload/Pequena-Historia-de-Inglaterra.pdf

Guerra, C. (2002). Fusiones Bancarias: El Caso Bancomer (Análisis de Notas Periodísticas e Investigación) (Tesis doctoral). Universidad Nacional Autónoma de México, México D.F. Recuperado de: http://www.economia. unam.mx/secss/docs/tesisfe/GuerraMC/tesis.html

Jiménez, A. (2000). Lecciones de Derecho Tributario. México D.F.: CENGAGE LEARNING.

Martínez, R. (2011). Constitución Política de los Estados Unidos Mexicanos, comentada (6ta. ed.). México D.F.: Oxford University Press.

Pérez, V. (2011). Argumentación Jurídica. México, D.F. : Oxford University Press.

Real Academia Española. (2014). Diccionario de la lengua española (23. ${ }^{a}$ ed.). Consultado en: https://dle.rae. es/?id=5hVbaEt

Rojas, D. (2013). Antecedentes del Derecho Bancario. Consultado en: https://www.clubensayos.com/Temas-Variados/Antecedentes-Historicos-Del-Derecho-Bancario/1407746.html

Tovar, I. \& Mas, M. (2019). Entrada del ejército trigarante a la Ciudad de México el 27 de septiembre de 1821. México: Editorial Raíces. Consultado en: https://relatosehistorias. $\mathrm{mx} /$ nuestras-historias/entrada-del-ejercito-trigarante-la-ciudad-de-mexico-el-27-de-septiembre-de-1821

Suprema Corte de Justicia de la Nación. (2011). Jurisprudencia 17/98. México, D.F.: Suprema Corte de Justicia de la Nación. Consultado en: https://sjf.scjn.gob.mx/SJFSist/Paginas/ResultadosV2.aspx?Epoca $=1$ e3e $10000000000 \&$ Apen$\mathrm{d}$ i c e $=10000000000000 \&$ Ex p r e - 
sion $=17 / 98 \&$ Dominio $=$ Rubro, Texto $\&$ TATJ $=2 \&$ Or den $=1 \&$ Clase $=$ Tesis BL \&bc $=$ Jurisprudencia . Resultados\&TesisPrincipal=TesisPrincipal\&InstanciasSeleccionadas $=6,1,2,50,7 \&$ Hits $=20$

Villarán, L. (2016). La Constitución peruana comentada. Perú: Servicios Gráficos JMD S.R.L. Recuperado de https://www.tc.gob.pe/wp-content/uploads/2018/10/ Constitucion_Peruana_Comentada.pdf

Weston, A. (2001). Las Claves de la Argumentación. España: Ariel. Recuperado de https://filosevilla2012. files.wordpress.com/2012/09/lasclavesdeargumentaciona-weston.pdf 
